\section{Parallel encoding within and between elementary stimulus dimensions}

\author{
D. ALAN ALLPORT \\ University of Reading, Reading RG6 2AL, England
}

Human ability to encode simultaneously different dimensions of a visual display was tested, using an "erasure" technique to control the time for which the visual information remained available for processing. Three separate vocabularies of test item were employed, one varying in terms of color and two in terms of form attributes. Simultaneous presentation of color and form stimuli gave evidence of nearly perfect parallel encoding of both types of attribute. Form-form combinations, on the other hand, indicated only partially simultaneous encoding of the primary form dimensions involved, It was suggested that, while primary encoding of different stimulus dimensions is simultaneous, within the same dimension encoding of discrete stimulus elements may occur seriatim.

The idea of dimensional selectivity or "set" in visual perception is an old one. Commonly the idea is taken to imply such results as, in tachistoscopic displays, enhanced accuracy of report for stimulus dimensions to which an $\mathrm{O}$ has been instructed to attend. However, the experimental evidence for dimensional selectivity, in this sense of the term, is remarkably slight. A recent critical review by Egeth (1967) could point to only one study using dimensionalized stimuli in which such an advantage could be claimed, once the effects of order or delay of report had been suitably controlled. Moreover, even this experiment (Harris \& Haber, 1963), contrary to the interpretation given by its authors and by Egeth, in fact failed to demonstrate any positive advantage of directing attention to particular stimulus attributes.

In Harris and Haber's experiment, 0 was instructed before each exposure either (1) to pay special attention to one of three stimulus dimensions ("emphasis instructions") or (2) to pay equal attention to all of them ("equal instructions"). In both cases, all three dimensions were to be reported, the order of report being specified only after the $1 / 10$-sec exposure. In a third condition, $\mathrm{O}$ was instructed in advance to report only the "emphasized" dimension ("one-only instructions"). The results show that, even in Os who were trained to rehearse their reports dimension by dimension (i.e., compatibly with the dimensionalized manner of report, so presumably favoring dimensional selectivity), the accuracy of report under equal instructions was higher over all dimensions and for all three positions of

*This research was supported by an equipment grant from the Medical Research Council. I thank Mrs, Alison Williamson for assistance in the preparation of stimulus materials. report order than it was, even for the emphasized dimension, under emphasis instructions! In other words, there was no positive advantage whatever from the unemphasized dimensions, on the other hand, accuracy was significantly worse, again at all positions of report order, while under one-only instructions performance was about at the level of first-reported dimensions under either equal or emphasis instructions (emphasized dimension). The net effect of emphasis instructions was then not to favor the emphasized dimensions but, quite simply, to prejudice the unemphasized ones. Selectivity, insofar as it was acting in Harris and Haber's experiment, was acting merely to reduce the accuracy of information on certain dimensions which would otherwise have been available.

The explanation for the absence of effects of dimensional selectivity may be, quite simply, that the information available in a visual display is initially encoded or abstracted into its constituent dimensions simultaneously; that is, different elementary stimulus dimensions or features can be encoded in parallel (Hypothesis 1), so that selection between dimensions is simply unnecessary. Any selective limitation on the accuracy of report from a complex tachistoscopic display should in this case be ascribed to the subsequent encoding of already dimensionalized information into verbal or other higher order categories (which may still be sequential), and/or memory losses at either of these levels of representation.

It should be of some interest, therefore, first to try to confirm the hypothesis of simultaneous encoding of elementary stimulus dimensions, and second to establish the limits, if any, on such parallel processing. To this end, we require a method of dissecting out the time required selective emphasis instructions. On the for the initial "read in" or abstraction of visual dimensions (the subject of this paper) from the remaining total latency of an identifying or other selective response.

\section{THE “ERASURE” PARADIGM}

An experimental paradigm meeting this requirement has been introduced by Sperling (1963). According to this paradigm, a test exposure containing an array of characters to be reported by 0 is terminated with the onset of a pattern of densely scattered fragments of the test items. Presentation of the second pattern is designed to cut short the time for which the "raw" or uncategorized information in the test exposure persists in iconic visual memory (Neisser, 1967). The extent to which this information is lost to further processing, or "erased," depends on a variety of local properties of both the test and masking contours, including their proximity (density) and contrast levels (cf. Kolers, 1962; Kinsbourne \& Warrington, 1964; Schiller, 1966). Optimum erasure appears to require a high density of scrambled contours, similar to those in the test items, and in all possible orientations on the masking field.

It is not known how far the erasure effect is due to active inhibition of old iconic information by the new, a mechanism which would be useful in preventing the persistence of iconic storage through successive eye movements, and how far to passive summation of the two, so that, with sufficiently complex stimuli, the combined icon is unreadable. Fortunately for the purposes of our experimental technique, the detailed mechanism or mechanisms of erasure are not important. What is important is that the arival of new iconic information should effectively terminate, more or less abruptly, the availability of the old. Then any information about the contents of the test exposure which appears in O's report must have been already encoded into some other (abstracted) representation, not similarly affected by the arrival of new contours, before the masking stimulus occurred. Consequently, by varying the interval (ISI) between the onsets of the two stimuli, the temporal characteristics of this primary encoding or abstracting process (which may still represent quite an early stage in the process of stimulus identification) can be measured.

It seems highly unlikely, on a number of grounds, that the encoding operation whose time course is measurable in this way represents complete stimulus identification, as Sperling $(1963,1967)$ has assumed. First, the ISIs involved are extremely short, such that, for example, Os can report one or more letters or digits at 
ISIs of only $20 \mathrm{msec}$, whereas the latency of an identifying response to these stimuli is of the order of $400 \mathrm{msec}$ or more. Second, and more fundamentally, it is reasonable to suppose that information which $\mathbf{O}$ is to report need only be encoded at the most elementary level in the recognition hierarchy beyond that of iconic representation, in order to escape the effects of iconic erasure. Certainly this would be the most efficient strategy for 0 . Further analysis and identification, on the basis of whatever stimulus features had thus been extracted from the icon, could occur after erasure of the latter. It is known from experiments on visual search (Neisser, 1963) that feature analysis can be carried out without engaging full stimulus identification. There seems even stronger reason to believe that this is what occurs, during the test exposure, under the more severe temporal constraints of the erasure situation.

Somewhat surprisingly, Neisser (1967) has taken the same extremely rapid increase of correct reports obtained in Sperling's (1963) experiment as evidence that erasure must have been incomplete. His argument is simply that, taken as a measure of the rate at which discrete characters can be identified ("read") from the display, obtained rates of $100 \mathrm{items} / \mathrm{sec}$ seem "extremely unlikely," compared with other estimates for rates of subvocal rehearsal. However, if we discard the assumption that the times involved are those for full identification (let alone articulation of the naming response), the argument loses its force.

\section{PARALLEL PROCESSING WITHIN OR} BETWEEN STIMULUS DIMENSIONS

Allport (1968) has shown that the rate of increase of correct reports with exposure duration (delay of the masking stimulus) differs radically for different kinds of test item. Thus the accuracy of report for discrete letters or digits increases nearly three times as rapidly as for Landolt rings. A possible explanation of this is as follows: Digits (and letters) can be discriminated from one another in terms of multiple alternative features. By Hypothesis 1 , therefore, $O$ should be able to encode different features from a number of spatially separate characters simultaneously. Landolt rings, on the other hand, differ from one another in terms of only one type of distinctive feature, the location of the break. Suppose now that, within any one visual dimension, processing capacity is limited and must be shared over different spatial locations in the display (Hypothesis 2). In this case, spatially parallel processing of objects such as Landolt rings would be severely limited or even impossible; hence, the much slower rate of gain of information obtained. Besides, since different digits in a display may also frequently share the same critical features, encoding of these items, too, can be only partially in parallel; hence, the finite, apparently continuous, initial rate of gain found (by Sperling, 1963, and others) for these items also.

The objective of the present experiment was to test, independently, Hypotheses 1 and 2. The basic design, using an erasure paradigm, was to present simultaneously stimulus items drawn from two different vocabularies of report: (1) in which items within the separate vocabularies are discriminated from one another on the basis of independent, nonoverlapping attributes or dimensions, and (2) in which the discrimination of items in both vocabularies depends on the analysis of common dimensions. In both cases, the accuracy of report was to be compared with that for each vocabulary presented singly. The "dimensions" selected, for the purpose of generating two sets of as nearly as possible independent attributes, were the quite gross ones of color and form, respectively. Within the latter, two vocabularies of form items (numerals and outline shapes) were then selected with a view to producing an appreciable overlap in their elementary distinctive features, but with no attempt at this stage to analyze these in detail.

If the conditions required in selecting these "dimensions" have been met, then (by Hypothesis 1) the accuracy of report about either form vocabulary at a given stimulus availability time should be unaffected (subsequent memory losses, etc., apart) by having simultaneously to take in information about color, and vice versa. On the other hand, where there is overlap between the two sets of distinctive features, i.e., in the simultaneous form-form combination, we predict (by Hypothesis 2) to that extent a decrement on one or both vocabularies.

However, if, contrary to Hypothesis 1, different visual dimensions are encoded serially, then the total number of items which can be correctly reported under simultaneous presentation at any given exposure duration should be, at best, the same as for one vocabulary alone, and regardless of which "dimensions" are presented together. This result should also be obtained if accuracy of report in the erasure paradigm is limited by the time required for full identification or verbal labeling of items, as suggested by Sperling $(1963,1967)$.

METHOD
Apparatus
The sequence of stimuli was presented
binocularly by means of a Scientific

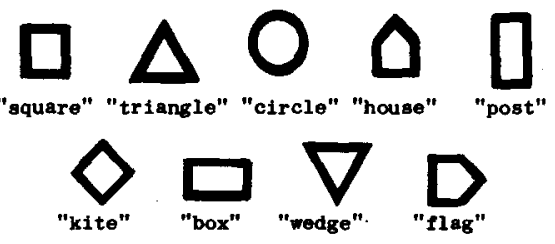

Fig. 1. Set of nine outline shapes (S) and names used to report them.

Prototype Model GB three-channel tachistoscope at a viewing distance of $4 \mathrm{ft}$.

\section{Stimulus Materials}

There were three separate vocabularies, or "dimensions," of test items: (1) outline geometrical shapes, (2) numerals, and (3) colors. The nine outline shapes are shown in Fig. 1. They were stenciled with a Gem Marker in colored ink, stroke width 0.15 in., and ranged in height from 0.75 in. ("box") to 1.20 in. ("post"). The numerals were 0-8 inclusive, printed in black Letraset Futura Medium Sheet STE 257, $0.35 \mathrm{in}$. high, stroke width $0.05 \mathrm{in}$. The three colors used were "red," "green," and "blue," corresponding approximately to Nos. 13 (deep R), 118 (deep YG), and 179 (deep B) on the ISCC-NBS color-name charts. 1

Test items were printed in a horizontal row of three items, separated by 1.4 in. center to center, on $5 \times 7$ in. matte white cards. The numerals, when present, were centered inside the outline shapes. Sets of 50 stimulus cards were prepared for each of the three single dimensions, outline shape (S), color (C), and numerals $(\mathrm{N})$, and for the three possible pairings of dimensions, SC, NC, and SN. Within each dimension, stimulus items were selected by means of a table of random numbers. subject to the constraint that the same item should not occur more than twice on any one card.

One-dimensional (1-D) stimuli. In each of three sets only one "relevant" dimension varied, while the "irrelevant" ones were held constant. Thus shapes (S) were drawn all in green ink, and colors (C) were in the form of outline squares. Numerals $(N)$ were printed inside green outline squares.

Two-dimensional (2-D) stimuli. For the three remaining sets of cards, two dimensions varied simultaneously and independently, while the third was held constant, viz, (1) numerals inscribed in squares of varying color (NC), (2) numerals inscribed in independently varying green outline shapes (SN), and (3) outline shape and color varied independently, without inscribed numerals (SC).

The masking field consisted of randomly scattered short strokes with the three colored Gem Markers. Strokes were made in all possible orientations, but not 

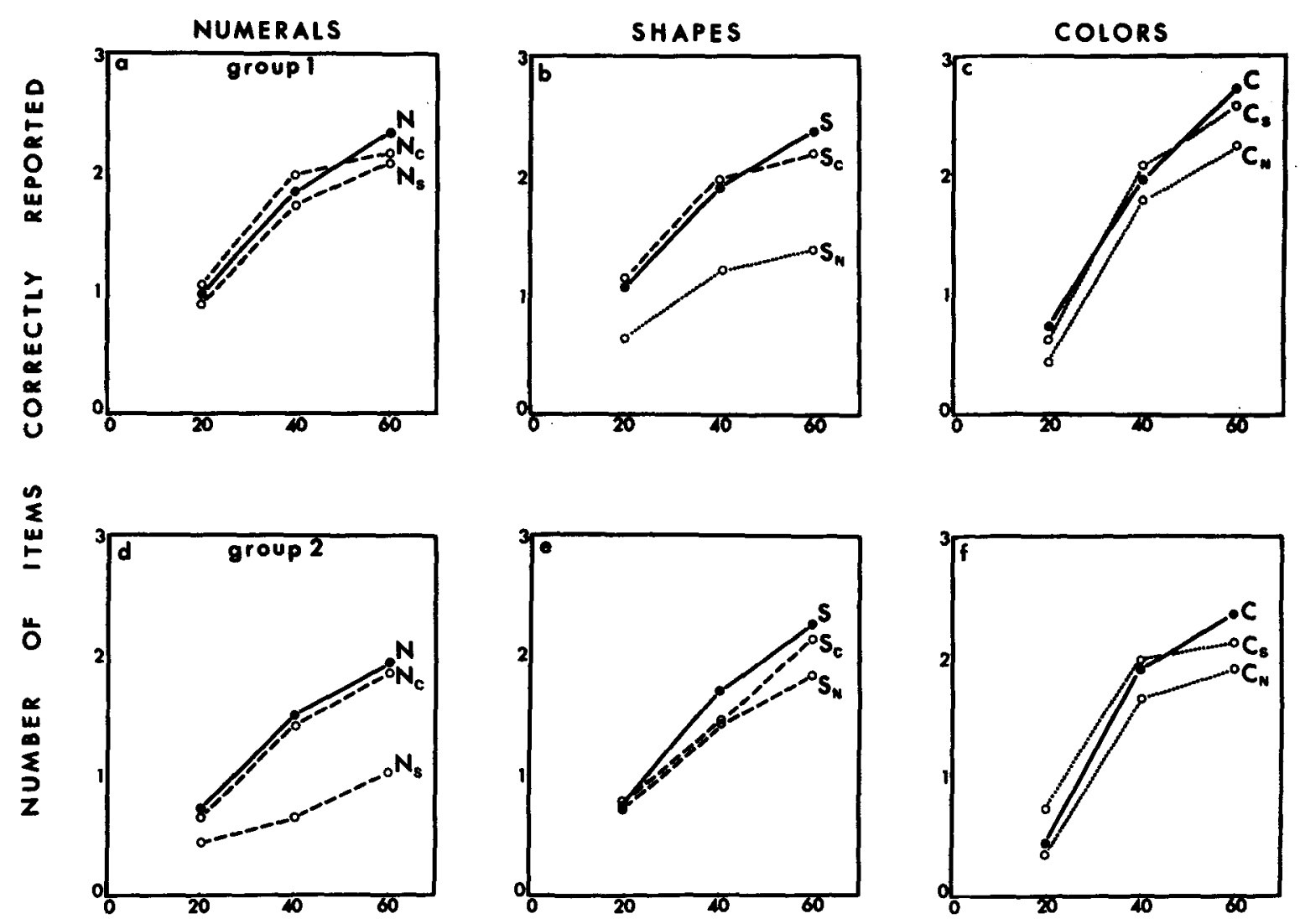

\section{EXPOSURE DURATION (MSEC)}

Fig. 2. Mean number of items reported correctly as a function of delay of the post-exposure masking stimulus, i.e., time available for the primary encoding of visual dimensions. The results are shown separately for each of the three vocabularies of test items and for the two groups of Os. Filled circles and solid lines represent results in the 1-D conditions; open circles and broken lines show results for the same dimension in the 2-D conditions. Within the latter, dashed lines show the dimension reported first, dotted lines the dimension reported second.

overlapping, and distributed in such a way as to cover, on average, $70 \%$ of the total surface area. Broken fragments of the numerals, again in all possible orientations, were superimposed on this pattern, scattered so as to cover an average $40 \%$ of the field. Eight closely similar but nonidentical versions of the masking field were generated in the same way. The particular pattern of masking field was changed at random intervals during each experimental session.

Between each trial, 0 observed a white adapting field containing a $2 \times 5$ in. horizontal outline rectangle. Luminance of the adapting, test, and masking fields (white area) was $18.0 \mathrm{fL}$, monitored periodically throughout the course of the experiment.

\section{Procedure}

When ready, $O$ fixated within the area of the rectangle in the adapting field. He triggered the onset of the test field by pressing a hand-held microswitch. The sequence of events on each trial was then: (1) test field on for a constant 20-msec duration, followed by (2) return of the adapting field for a variable interval, followed in turn by (3) the masking field on for $2.0 \mathrm{sec}$, and finally (4) retum of the adapting field. Effective availability times of the test items prior to onset of the masking field were $20 \mathrm{msec}$ (i.e., zero delay of the masking field), $40 \mathrm{msec}(20-\mathrm{msec}$ delay), and $60 \mathrm{msec}$ (40-msec delay). In this way, by holding physical exposure duration of the test items constant, differences in legibility of the test items at different effective exposure intervals due simply to luminance or contrast summation effects (Eriksen, 1966; Kahneman, 1965) were controlled.

$O$ 's task was to report as many of the relevant test items as possible. He was always instructed in advance which dimension(s) would vary, and therefore which he was to report. $O$ said aloud and then wrote his report in a prepared booklet. He was instructed to report the items from left to right, leaving blanks if necessary. In the 2-D conditions, $O$ reported as much as possible of one dimension before reporting the other dimension but was instructed to "attend equally to both." The order in which the dimensions were to be reported was also specified in advance and remained constant for any $O$ throughout the experiment. Reporting by dimensions in this way was found, in a preliminary experiment, to yield rather higher scores that did reporting by positions (cf. Harris \& Haber, 1963). The particular order in which the two dimensions were reported had relatively little effect, at least for the two form-color combinations (SC and $\mathrm{NC}$ ), with not more than three items to be reported for each dimension. In this experiment, therefore, Os always reported SC and NC in a fixed order, color reported second. On the other hand, order of report in the form-form combination (SN) had a large effect. In the present experiment, half the Os reported numerals first (Group 1), while the other half reported shapes first (Group 2).

On each trial, following $O$ 's report, the correct version was read aloud to him and a fresh stimulus card inserted.

Design

Each of 12 Os served for one practice 
Table 1

Total Number of Items Correct and Comparisons of Combined Scores in $1 D$ and $2 D$ Conditions

\begin{tabular}{|c|c|c|c|c|}
\hline \multirow{2}{*}{\multicolumn{2}{|c|}{$\begin{array}{c}\text { Exposure } \\
\text { Duration } \\
\text { (Msec) }\end{array}$}} & \multicolumn{3}{|c|}{ 1D Conditions } \\
\hline & & \multirow{2}{*}{$\begin{array}{c}\mathrm{N} \\
0.85 \\
(0.37)\end{array}$} & \multirow{2}{*}{$\frac{S}{0.94}$} & \multirow{2}{*}{$\begin{array}{c}\mathrm{C} \\
0.58 \\
(0.24)\end{array}$} \\
\hline 20 & $\begin{array}{l}\text { Mean } \\
\text { (SD) }\end{array}$ & & & \\
\hline 40 & $\begin{array}{l}\text { Mean } \\
\text { (SD) }\end{array}$ & $\begin{array}{c}1.66 \\
(0.44)\end{array}$ & $\begin{array}{c}1.79 \\
(0.34)\end{array}$ & $\begin{array}{c}1.94 \\
(0.49)\end{array}$ \\
\hline 60 & $\begin{array}{l}\text { Mean } \\
\text { (SD) }\end{array}$ & $\begin{array}{c}2.13 \\
(0.39)\end{array}$ & $\begin{array}{c}2.31 \\
(0.36)\end{array}$ & $\begin{array}{c}2.68 \\
(0.29)\end{array}$ \\
\hline
\end{tabular}

\begin{tabular}{cc}
\hline 2D Conditions \\
Numeral-Color \\
\hline
\end{tabular}

\begin{tabular}{|c|c|c|c|c|c|c|}
\hline \multirow{3}{*}{\multicolumn{2}{|c|}{$\begin{array}{c}\text { Exposure } \\
\text { Duration } \\
\text { (Msec) }\end{array}$}} & & & & \multirow{2}{*}{\multicolumn{2}{|c|}{$\mathbf{P}$}} \\
\hline & & \multirow{3}{*}{$\begin{array}{c}\mathrm{NC} \\
0.83 \\
(0.36)\end{array}$} & \multirow{3}{*}{ 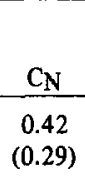 } & \multirow{3}{*}{$\frac{\begin{array}{c}(\mathrm{N}+\mathrm{C})- \\
\left(\mathrm{NC}+\mathrm{C}_{\mathrm{N}}\right)\end{array}}{0.18}$} & & \\
\hline & & & & & \multirow{2}{*}{$\frac{t}{\text { n.s. }}$} & \multirow{2}{*}{$\begin{array}{l}\text { (Scheffé) } \\
\text { n.s. }\end{array}$} \\
\hline 20 & $\begin{array}{l}\text { Mean } \\
\text { (SD) }\end{array}$ & & & & & \\
\hline 40 & $\begin{array}{l}\text { Mean } \\
\text { (SD) }\end{array}$ & $\begin{array}{c}1.69 \\
(0.50)\end{array}$ & $\begin{array}{c}2.01 \\
(0.57)\end{array}$ & 0.19 & n.s. & n.s. \\
\hline 60 & $\begin{array}{l}\text { Mean } \\
\text { (SD) }\end{array}$ & $\begin{array}{c}2.15 \\
(0.43)\end{array}$ & $\begin{array}{c}2.35 \\
(0.43)\end{array}$ & 0.76 & $<0.001$ & n.s. \\
\hline
\end{tabular}

Shape-Color

\begin{tabular}{|c|c|c|c|c|c|c|}
\hline & & \\
\hline & & \multirow[b]{2}{*}{$\mathrm{s}_{\mathrm{C}}$} & \multirow[b]{2}{*}{$\mathrm{CS}_{\mathrm{S}}$} & \multirow{2}{*}{$\begin{array}{l}(S+C)- \\
\left(S_{C}+C_{S}\right) \\
\end{array}$} & \multicolumn{2}{|c|}{$\mathbf{P}$} \\
\hline & & & & & $\mathrm{t}$ & (Scheffé) \\
\hline 20 & $\begin{array}{l}\text { Mean } \\
\text { (SD) }\end{array}$ & $\begin{array}{c}0.95 \\
(0.44)\end{array}$ & $\begin{array}{c}0.68 \\
(0.41)\end{array}$ & -0.11 & n.s. & n.s. \\
\hline 40 & $\begin{array}{l}\text { Mean } \\
\text { (SD) }\end{array}$ & $\begin{array}{c}1.69 \\
(0.50)\end{array}$ & $\begin{array}{c}2.01 \\
(0.57)\end{array}$ & 0.03 & n.s. & n.s. \\
\hline 60 & $\begin{array}{l}\text { Mean } \\
\text { (SD) }\end{array}$ & $\begin{array}{c}2.15 \\
(0.43)\end{array}$ & $\begin{array}{c}2.35 \\
(0.43)\end{array}$ & 0.49 & $<0.01$ & n.s. \\
\hline
\end{tabular}

\begin{tabular}{|c|c|c|c|c|c|c|}
\hline & & \multicolumn{5}{|c|}{ Numeral-Shape } \\
\hline & & \multirow[b]{2}{*}{$S_{N}$} & \multirow[b]{2}{*}{ Ns } & \multirow{2}{*}{$\begin{array}{l}(S+N)- \\
\left(S_{N}+N_{S}\right)\end{array}$} & \multicolumn{2}{|c|}{$\mathbf{P}$} \\
\hline & & & & & $t$ & (Scheffé) \\
\hline 20 & $\begin{array}{l}\text { Mean } \\
\text { (SD) }\end{array}$ & $\begin{array}{c}0.70 \\
(0.27)\end{array}$ & $\begin{array}{c}0.67 \\
(0.47)\end{array}$ & 0.42 & $<0.01$ & n.s. \\
\hline 40 & $\begin{array}{l}\text { Mean } \\
\text { (SD) }\end{array}$ & $\begin{array}{c}2.28 \\
(0.57)\end{array}$ & $\begin{array}{c}1.18 \\
(0.65)\end{array}$ & 0.99 & $<0.001$ & $<0.05$ \\
\hline 60 & $\begin{array}{l}\text { Mean } \\
\text { (SD) }\end{array}$ & $\begin{array}{c}1.61 \\
(0.63)\end{array}$ & $\begin{array}{c}1.56 \\
(0.64)\end{array}$ & 1.27 & $<0.001$ & $<0.005$ \\
\hline
\end{tabular}

Note-n.s. $=$ not significant

and two experimental sessions of about $50 \mathrm{~min}$ each, as nearly as possible on consecutive days. In the practice session, Os were familiarized with the set of nine outline shapes, and practiced naming them aloud from a large array, to a criterion of 60 names $/ \mathrm{min}$. The remainder of this session consisted of 90 practice trials, covering each of the six experimental conditions. All the 1-D stimuli were given in one experimental session, and all the 2-D in the other. Six Os experienced the 1-D conditions first and six the 2-D conditions (three of Group 1 and three of Group 2, in each case). The same dimension remained "relevant" for a block of 36 trials. Exposure duration (delay of masking stimulus) was changed after every 12 th trial. The first two trials in each new duration were left unscored. Within each session, the order of presentation of the
(Groups 1 and 2). The results of the 2-D conditions are, therefore, divided in each case between the two relevant diagrams for their component dimensions. The principal comparisons to be made are between the scores on any dimension under 1-D conditions (filled circles, solid lines) and the corresponding score when $\mathbf{O}$ is also loaded on another dimension indicated by the subscripted letter (open circles, broken lines).

There is, as is clear, a very large main effect of exposure duration $[F(2,20)=398.97, p<.001]$, which agrees with previous studies using the erasure paradigm (e.g., Sperling, 1963), although this is not the subject of primary interest here. The overall results for the two groups (order of report) did not differ significantly $[F(1,10)=3.05, p>.1]$. However, there were significant effects due to dimensions $[F(8,80)=10.08$, $\mathrm{p}<.001]$, and to the interaction of dimension with order of report $[F(8,80)=4.97, p<.001]$. The pattern of results within these overall effects was further analyzed by Newman-Keuls multiple comparisons as follows:

Taking the results for numerals first, it is clear from Fig. 2 (a and d) that accuracy of report on this dimension is substantially unaffected by simultaneously having to encode information on either of the other two dimensions, except in one case, the numeral-shape combination when numerals are reported last, i.e., Condition $\mathrm{N}_{S}$, Group 2. In this condition, the decrement over the 1-D score is significant at all three exposure durations $(p<.05$ at $20 \mathrm{msec}$, and $p<.001$ at 40 and $60 \mathrm{msec}$ ). None of the other differences between 1-D and 2-D performance on numerals approaches significance.

The results for shapes (Figs. $2 \mathrm{~b}$ and $2 \mathrm{e}$ ) presented a similar picture. Again, the principal decrement is in the numeral-shape combination, in this case when shapes are reported last, i.e., Condition $S_{\mathrm{N}}$, Group 1 $(\mathrm{p}<.01$ at $20 \mathrm{msec}$, and $\mathrm{p}<.001$ at 40 and $60 \mathrm{msec}$ ). None of the other 2-D scores is significantly below its 1-D equivalent, except once more in the numeral-shape combination at $60 \mathrm{msec}$ when shapes are reported first, i.e., Condition $S_{N}$, Group 2 $(\mathrm{p}<.05)$

Accuracy of report of color (Figs. 2c and 2f) is largely unaffected by simultaneously having to take in information about either of the two form dimensions, even though in all cases color items were reported last. At 20- and 40-msec exposures there was no statistically significant difference between 1-D and 2-D performance. Only at $60 \mathrm{msec}$, the combination with numerals, i.e., $\mathrm{C}_{\mathrm{N}}$, showed a significant drop relative 
to the 1-D score (Group 1, $\mathrm{p}<.01$; Group 2, $p<.001$ ), and for Group 2 the combination with shapes, i.e., $\mathrm{C}_{S}$, also showed a decrement $(\mathrm{p}<.01)$. These latter effects, found only at $60 \mathrm{msec}$, are plausibly due to some sort of memory limitation, i.e., to partial forgetting of the already encoded color items during the time taken to report two or three items on the form dimension, rather than to any intrinsic limitation on simultaneous intake. At $40 \mathrm{msec}$, when fewer items are available on the dimension reported first, Conditions $\mathrm{C}_{\mathrm{S}}$ and $\mathrm{C}_{\mathrm{N}}$ are as accurate as $\mathrm{C}$ alone.

A more severe test of Hypothesis 1 is provided by comparing the total number of items correct, regardless of dimension, within each 2-D condition, with the sum of scores obtained on the same dimensions under 1-D conditions. Since the order of report is unimportant for this, we can combine the results in Groups 1 and 2 for all comparisons. The results are shown in this way in Table 1. Significance levels are given both for the results of $t$ tests and of the more conservative Scheffé test. (We are not strictly concerned here with the numeral-shape combination, included simply for completeness. This condition does not provide a suitable test of Hypothesis 1, and was introduced to test Hypothesis 2 . The results here merely confirm the Newman-Keuls analysis described above, supporting the predictions of Hypothesis 2.) In the two form-color combinations, the total differences between 1-D and 2-D performance (Columns 6 and 11) are very small indeed and do not come near statistical significance at either 20 or $40 \mathrm{msec}$. As was already indicated by the Newman-Keuls comparisons, performance at $60 \mathrm{msec}$ in these 2-D conditions does show a small but significant drop, due largely to the color items. Multiple $t$ tests of course increase the possibility of a Type I error, but since our Hypothesis 1 is here the null hypothesis this risk is perhaps justifiable. On the Scheffé test, included as a safeguard, none of the form-color combinations reached even a $10 \%$ significance level. However, the main point is that over 20 and $40 \mathrm{msec}$ no decrement can be detected, even by the strongest statistical tests. Failure to reject the null hypothesis in these conditions provides rather strong support for Hypothesis 1.

\section{DISCUSSION}

These results permit us conclusively to reject the hypothesis (Sperling, 1963, 1967; and others) that data obtained in the "erasure" paradigm reflect seriatim verbal labeling or identification of test items, as discussed in the introduction. Clearly, the rate of gain of information from the display in the 1-D and 2-D conditions is not limited by the number of lexical units needed in its report. The results provide correspondingly strong support for Hypothesis 1, namely, that different elementary stimulus dimensions may be encoded simultaneously.

The predictions of Hypothesis 2, that within a given dimension parallel processing is restricted, were also clearly supported. The differences between simultaneous form-form and form-color conditions point unambiguously to visual rather than verbal coding limitations. Nevertheless, even in the critical numeral-shape combination, evidence of a large amount of parallel processing remains. The total number of items reported correctly from both vocabularies under 2-D conditions amounted to $76 \%$, $72 \%$, and $71 \%$ of the summed scores of numerals and shapes in the 1-D conditions, at 20,40 , and $60 \mathrm{msec}$, respectively. This figure should be limited to $50 \%$ under strictly serial encoding of one vocabulary after the other. It follows that our principal conclusion, regarding the parallel encoding of different stimulus dimensions, is not a special case of the color and form combination alone, but applies between presumably different form dimensions also. Indeed, in Condition SN one O showed no drop on either dimension over the 1-D condition. The rest all suffered some loss of accuracy at least on the dimension reported second, and some on both dimensions. Since there was no comparable loss when the second-reported dimension was color (following report of the same form dimensions), and since the amount lost in Condition SN was a constant proportion of the 1-D score over all durations, it seems reasonable to exclude immediate memory losses as the main source of the deficit on the second form dimension.

How far can these conclusions be generalized? Preliminary results of a similar experiment, but using different sets of colors and solid shapes and varying the size of sets, are identical as regards Hypothesis 1 , suggesting that the capacity for simultaneous encoding of color and form information is independent, within broad limits, of the particular colors and forms and of vocabulary size. In the latter experiment, a combination of numerals superimposed on solid shapes produced more nearly complete parity of performance between 1-D and 2-D conditions, i.e., very little interference. Since the solid shapes were intuitively much less similar to the numerals (fewer "dimensions" in common?) than were the outline shapes used in the main experiment, this result is also to be expected on Hypothesis 2.

To the extent that primary visual dimensions are encoded simultaneously in the nervous system, dimensional selectivity, that is selection between primary dimensions, is of course simply unnecessary. Just which are "primary" dimensions in this sense is a question for immediate future research. A promising approach to this problem may lie in exploring the types of stimuli which do or do not exhibit mutual interference, using the general technique defined by the foregoing experiment. Where, if at all, in the perceptual hierarchy parallel operation more generally breaks down, so that serial, and hence, when time or memory is limited, selective, processing becomes necessary, is another question.

\section{REFERENCES}

ALLPORT, D. A. The rate of assimilation of visual information. Psychonomic Science, 1968, 12, 231-232.

EGETH, H. Selective attention. Psychological Bulletin, 1967, 67, 41-57.

ERIKSEN, C. W. Temporal luminance summation effects in backward and forward masking. Perception \& Psychophysics, 1966, 1, 87-92.

HARRIS, C. W., \& HABER, R. N. Selective attention and coding in visual perception. Journal of Experimental Psychology, 1963, 65, 328-333.

KAHNEMAN, D. Exposure duration and effective figure-ground contrast. Quarterly Journal of Experimental Psychology, 1965, 17, 308-314.

KINSBOURNE, M., \& WARRINGTON, E. Interaction between brief asynchronous visual stimuli. Paper presented at meeting of the Experimental Psychology Society, Cambridge, April 1964.

KOLERS, P. A. Intensity and contour effects in visual masking. Vision Research, 1962, 2, 277-294.

NEISSER, U, Decision-time without reaction-time: Experiments in visual scanning. American Journal of Psychology, 1963, 76, 376-385.

NEISSER, U. Cognitive psychology. New York: Appleton-Century-Crofts, 1967.

SCHILLER, P. H. Forward and backward masking as a function of relative overlap and intensity of test and masking stimuli. Perception \& Psychophysics, 1966, 1, 161-164.

SPERLING, G. A model for visual memory tasks. Human Factors, 1963, 5, 19-31.

SPERLING, G. Successive approximations to a model for short-term memory. In A. F. Sanders (Ed.), Attention and performance. Amsterdam: North Holland, 1967.

\section{NOTE}

1. ISCC-NBS Centroid Color Charts, Standard Sample No. 2106, obtainable from the Office of Standard Reference Materials, Room 215, Chemistry Building, National Bureau of Standards, Washington, D.C. 20234.

(Accepted for publication October 30, 1970.) 